\title{
Design and Structural Analysis of Lifting Arm in Processing Lift
}

\author{
S. F. Sakore, K. A. Mahajan \\ (Department of Mechanical Engineering, M. E. S. College of Engineering, S. P. Pune University, India)
}

\begin{abstract}
In industries it is required to assemble the structures like pressure vessel on overhead positions. This process needs lifting devices to reach up to working location. To assemble such structures, various joining operations need to be performed such as welding in overhead position. This work includes the redesign of existing lifting platform system with tilting joint so that the operations can be performed easily and more efficiently. In short the square shaped platform changed with semicircular shape platform and accordingly changing parameters are validated. Solution to cover more radial distance for operation on pressure vessels outer surface with load calculations and boundary conditions also working of tilting arm is validated with stresses and deflection coming on titling joints. Also structural behavioral results are compared and validated.
\end{abstract}

Keywords - FEA, Johnson Method, Lifting Arm, L-Bracket, Optimum Design.

\section{INTRODUCTION}

In assembly of pressure vessels, the joining processes/welding are performed on top head position which becomes too hectic and less efficient. The current system includes a standing cage from where the operator performs these operations. But due to the less width of the cage and improper design of the cage very less area of pressure vessel is worked (as the vessel is cylindrical in shape). This work includes the redesign of the system and its validation. A new system design is proposed with proper shape and size of standing cage. For required movement of the cage, the cage is attached to be with pivot joint. The lift of the cage is hydraulically operated. [1]

\section{PROBLEM STATEMENT}

In the current system as shown in Fig.1, it is observed that due to the shape and size of the standing cage, it becomes difficult for operator to weld / join maximum area of pressure vessel. Need to replace square platform into semicircular platform. Hence, a system with proper standing cage needs to be redesign so that maximum area of pressure vessel can be operated. Tilting is to be made with $\mathrm{L}$ bracket and tilting joints.

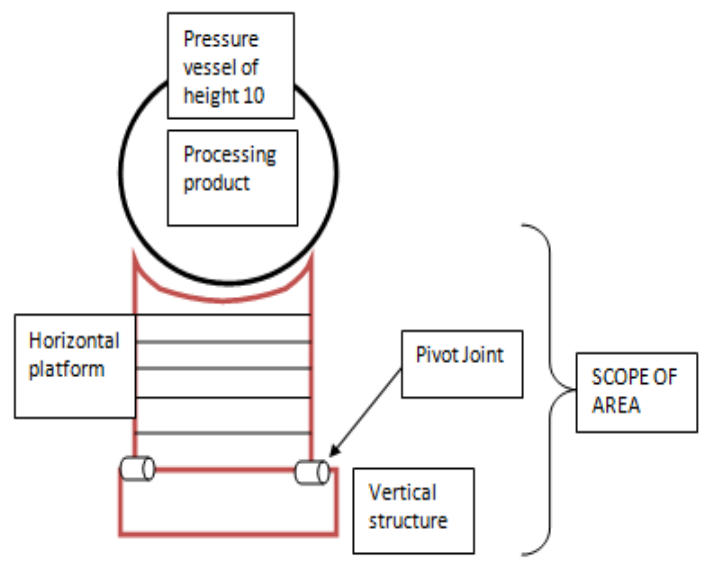

Fig.1. Layout of lifting structure

\section{THEROTICAL DESIGN}

3.1 Design of Semicircular Platform:

In this work, existing square platform is replaced by semi-circular platform. New platform development as shown in Fig.2 is carried out with the dimensions of bigger pressure vessel size of diameter i.e., 
$1750 \mathrm{~mm}$. So here we consider $1800 \mathrm{~mm}$ of platform internal diameter and $50 \mathrm{~mm}$ clearance between working object and lifting assembly should be there.[2]

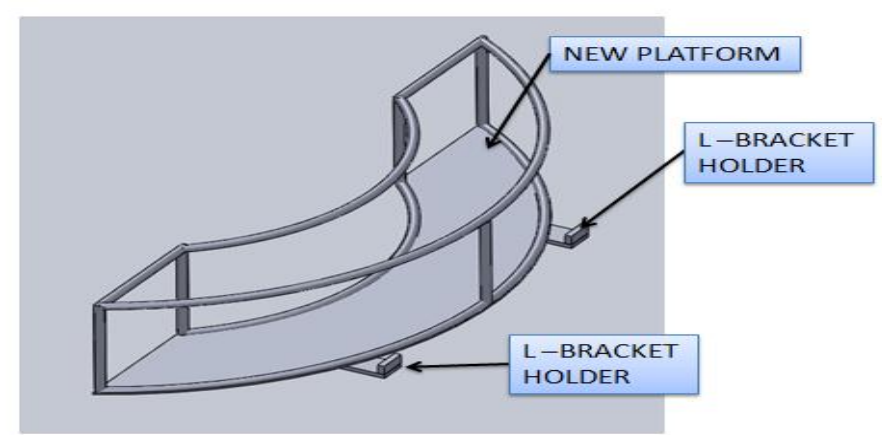

Fig.2. CAD model of semi-circular platform

\subsection{Tilting Joint design:}

In this design, hollow strut is used to lift maximum load of $5000 \mathrm{~kg}$ as shown in Fig 3.

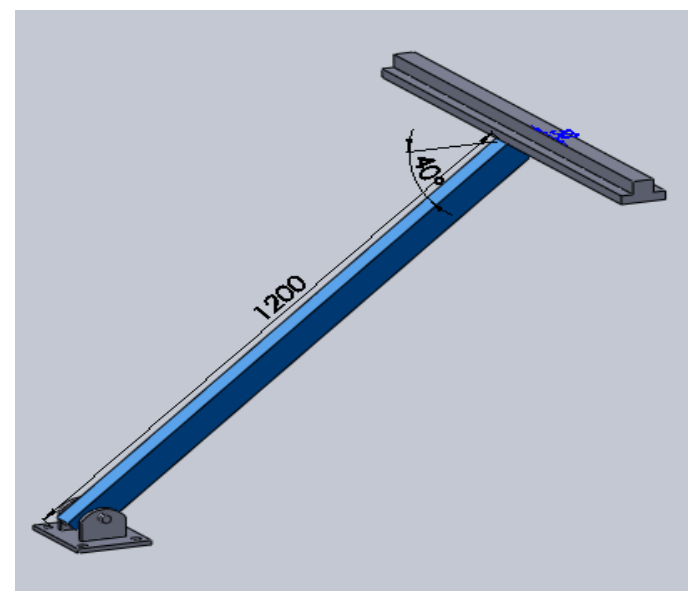

Fig.3. CAD model of lifting arm (40 tilt)

Tilting joint assembly model as shown in Fig.4 and also the CAD model is shown in Fig.5.

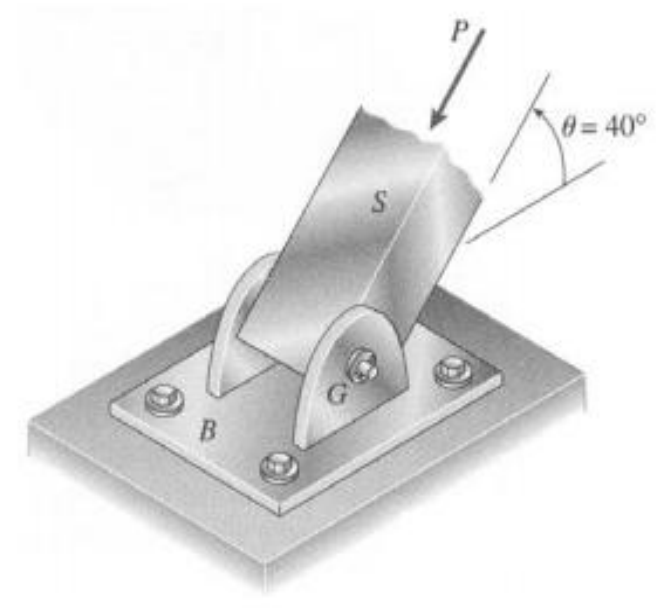

Fig.4. Tilting Joint assembly 
Where,

$\mathrm{S}=$ Strut, $\mathrm{G}=$ gusset, $\mathrm{B}=$ Anchor bolts, $\mathrm{P}=\mathrm{Pin}$

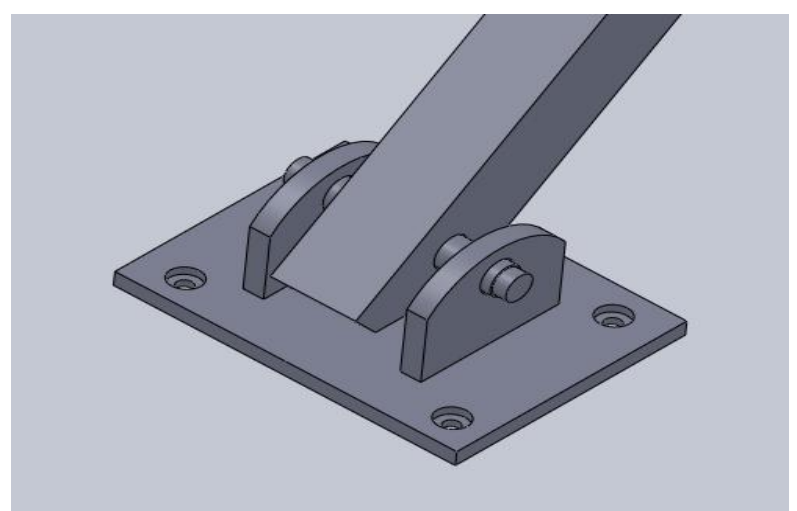

Fig.5. CAD model of tilting Joint assembly

Measured values of the assembly components are shown in Table 1:

Table 1: Dimensions of Components

\begin{tabular}{|l|c|}
\hline \multicolumn{1}{|c|}{ Components } & Value $(\mathrm{mm})$ \\
\hline Thickness of strut, $\mathrm{t}$ & 10 \\
\hline Thickness of gussets, $\mathrm{t}_{\mathrm{G}}$ & 15 \\
\hline Diameter of anchor bolt, $\mathrm{d}_{\text {bolt }}$ & 12 \\
\hline Thickness of base plate, $\mathrm{t}_{\mathrm{B}}$ & 10 \\
\hline Diameter of pin, $\mathrm{d}_{\mathrm{pin}}$ & 20 \\
\hline
\end{tabular}

3.3. Calculations: [3]

$\sigma=\frac{\text { Bearing stress between struts and pin: }}{2\left(\operatorname{td}_{\text {pin }}\right)}$
$\sigma=125 \mathrm{MPa}$

Bearing Stress between pin and gussets

$\sigma=\frac{\mathrm{P}}{2\left(\mathrm{t}_{\mathrm{G}} \mathrm{d}_{\text {pin }}\right)}$

$\sigma=83.3 \mathrm{MPa}$

Bearing Stress between anchor bolts and base plate

$\sigma=\frac{P \cos \theta}{4\left(t_{B} d_{\text {bolt }}\right)}$

$\sigma=79.8 \mathrm{MPa}$

Shear stress in anchor bolts

$\tau=\frac{\left(\frac{P \cos \theta}{4}\right)}{\pi \frac{d_{b o l t}^{2}}{4}}$

$\tau=84.7 \mathrm{MPa}$

- Shear stress in anchor bolts $=84.7 \mathrm{MPa}$

- Bearing Stress between anchor bolts and base plate $=79.8 \mathrm{MPa}$

- Bearing Stress between pin and gussets $=83.3 \mathrm{MPa}$

6th National Conference RDME 2017, 17th- 18th March 2017.

M.E.S. College of Engineering, Pune. 411001 
- Bearing stress between struts and pin $=125 \mathrm{MPa}$

3.4 L joint lifting behavior:

Due to applied load stress sand deflection generated in the body. CAD model of L-bracket is as shown in Fig.6.

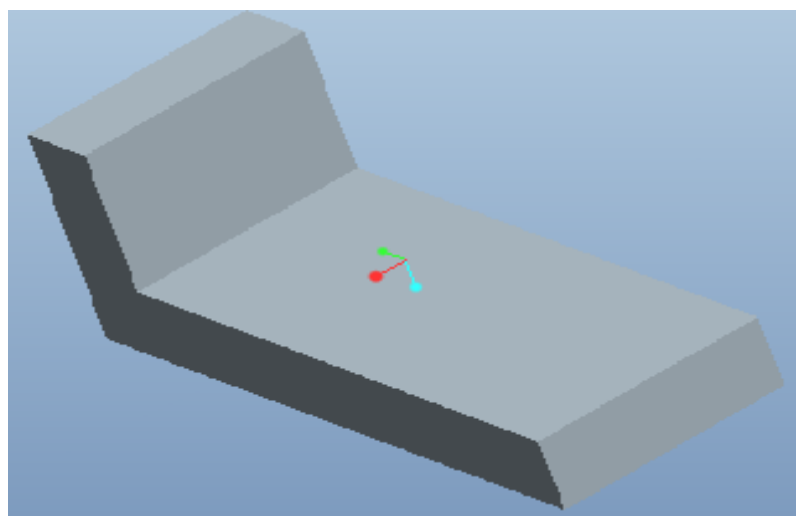

Fig.6. CAD model of L-Bracket
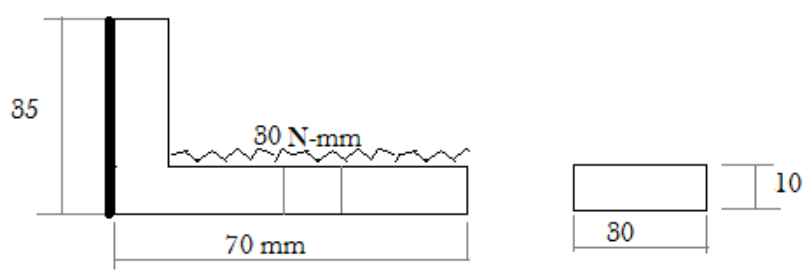

Fig.7. FBD of L-Bracket

As seen from the FBD as shown in Fig.7,

Maximum bending moment, $\mathrm{M}=73500 \mathrm{~N}-\mathrm{mm}$

Moment of inertia, $I=\frac{b t^{g}}{12} I=\frac{30 \times 10^{g}}{12}$

$\mathrm{I}=2500 \mathrm{~mm}^{4}$

The bending stress in the member is calculated as Moment of inertia, $I=\frac{b t^{g}}{12}$

$\mathrm{I}=\left(30 \times 10^{3}\right) / 12$

$\mathrm{I}=2500 \mathrm{~mm}^{4}$

The bending stress in the member is calculated as,

$\frac{\mathrm{M}}{\mathrm{I}}=\frac{a}{\mathrm{y}}$

$\frac{73500}{2500}=\frac{\sigma}{4}$

Bending Stress $=\sigma=147.00 \mathrm{~N} / \mathrm{mm}^{2}$

Deflection is given by, 


$$
\begin{gathered}
\delta=\frac{w^{4}}{8 \mathrm{EI}} \\
\delta=\frac{30 \times 70^{4}}{8 \times 200 \times 10^{\mathrm{a}} \times 2500} \\
\delta=0.18007 \mathrm{~mm}
\end{gathered}
$$

Hence, Maximum bending stress developed in the member $=147.00 \mathrm{~N} / \mathrm{mm}^{2}$ and

Maximum deflection of the member $=0.18007 \mathrm{~mm}$

\section{MATERIAL SELECTION}

\subsection{Optimum Material Selection by Johnson Method:}

Optimum design of mechanical element is the selection of material and values for independent geometrical parameters with explicit objective of either minimizing most significant undesirable effect or maximizing a most significant functional requirement, making in the design procedure that the mechanical element satisfies other functional requirements and that other undesirable effects are kept within tolerable limits. [4]

\subsection{Objective of optimum design:}

For any design problem, varieties of solutions are available. Solution of the problem is performance, cost, safety and robustness requirement etc. These solutions complete this requirement. Now a day, selection of the best available design solution is very important parameter. Optimization techniques are help perfectly to select the best design solution among the available solutions. [4]

In design of any mechanical element, a number of design parameters are used. These design parameters, which are related to each other by number of design equations, can be broadly classified three basic groups. [5]

i) Functional requirement parameters

ii) Material properties

iii) Geometrical parameters

4.3 The geometrical parameters:

$\mathrm{W}=$ weight of plate, $\mathrm{Kg}$

$\mathrm{w}=$ weight density of material, $\mathrm{Kg} / \mathrm{mm}^{3}$

$\mathrm{b}=$ width of plate, $\mathrm{mm}$

$1=$ length of plate, $\mathrm{mm}$

$\mathrm{t}=$ thickness of plate, $\mathrm{mm}$

$\mathrm{K}=$ stiffness of plate

$\sigma_{\mathrm{b}}=$ bending stresses, $\mathrm{N} / \mathrm{mm}^{2}$

$\mathrm{F}=$ applied force, $\mathrm{N}$

$\mathrm{N}_{\mathrm{f}}=$ factor of safety

$\mathrm{S}_{\mathrm{b}}=$ bending strength

$\mathrm{S}_{\mathrm{y}}=$ yield strength

Primary Design Equation (P.D.E):

Weight $(\mathrm{W})$ per unit length $=$ weight density $\times$ volume of plate

$\mathrm{W}=\mathrm{w} \times(\mathrm{b} \times \mathrm{l} \times \mathrm{t})$

Subsidiary design equation (S.D.E):

Bending stress $=\mathrm{F} \times \mathrm{L} \times \mathrm{Y} \times 12 / \mathrm{bt}^{3}$

From Eq. 1 \& 2

$\mathrm{W}=\mathrm{Kx} \mathrm{W} / \mathrm{Sy}^{0.5}$

The properties of the material are as shown in Table 2. From above equation 3, it is possible to evaluate weight density of various steels which directly affects the weight of material. Among above tabulated results, weight 
factor $\left(\frac{w}{\sqrt{S_{y}}}\right)$ for alloy steel is lower than any other type of steel so it is justified that SS 309 is optimal material for structure assembly.

Table 2: Material Properties [4]

\begin{tabular}{|c|c|c|c|}
\hline Materials & $\begin{array}{c}\text { Weight } \\
\text { Density } \\
\mathrm{W}\end{array}$ & $\begin{array}{c}\text { Yield } \\
\text { strength } \\
\mathrm{S}_{\mathrm{Y}}\end{array}$ & $\frac{\mathrm{w}}{\sqrt{\mathrm{S}_{\mathrm{Y}}}}$ \\
\hline SS 304 & 78480 & 205 & 5481.28 \\
\hline SS 316 & 78480 & 205 & 5481.28 \\
\hline SS 310 & 78744.87 & 210 & 5433.91 \\
\hline SS 309 & 78480 & 325 & 4353.29 \\
\hline
\end{tabular}

\section{CAE ANALYSIS}

The finite element analysis is performed to validate the design of tilting arm and L-joint. The commercially available software ANSYS is used to perform finite element analysis.[6]

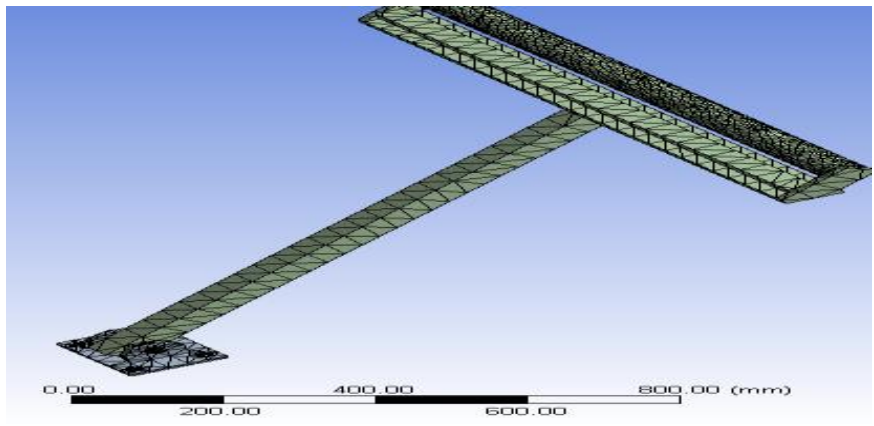

Fig.8. Meshed model of tilting arm

The above Fig. 8 shows the meshed model of the tilting arm. Meshing is done using ANSYS workbench. The tilting arm is meshed with 20907 tetrahedral elements. The boundary conditions applied are shown in the following Fig.9. The bottom plate is fixed and load of $50000 \mathrm{~N}$ is applied on the lifting arm.

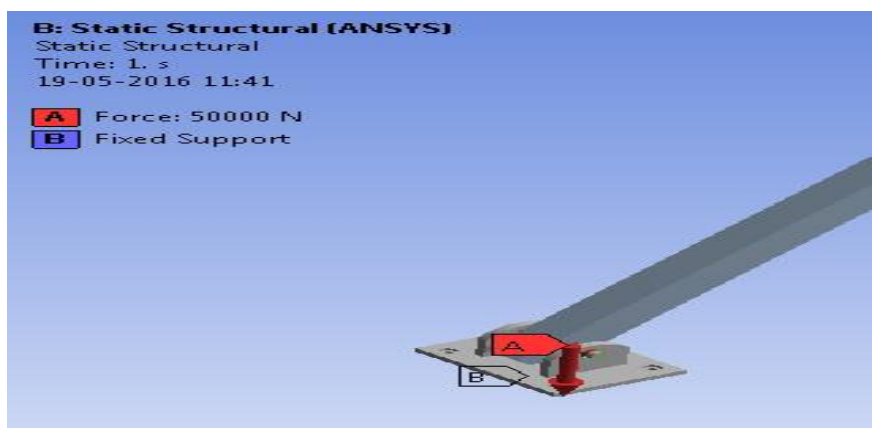

Fig.9. Boundary Conditions

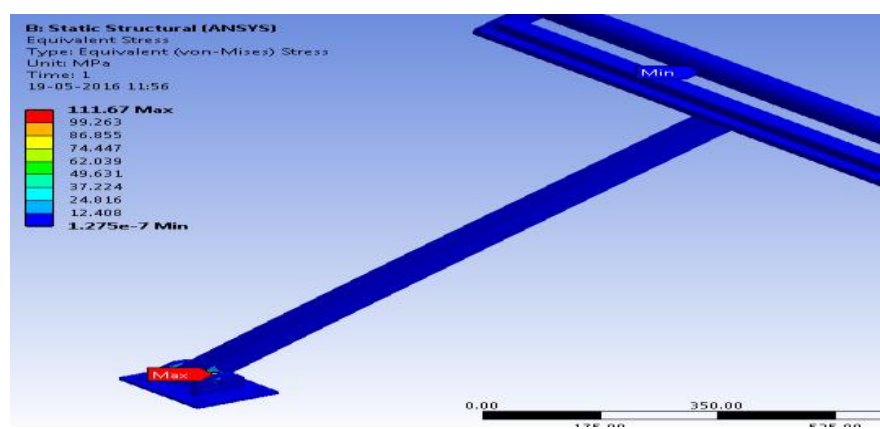

Fig.10. Von-mises stress on lifting arm for $50000 \mathrm{~N}$ 
The finite element simulation shows maximum von-mises stresses at the bottom of the tilting arm. The maximum von-mises stresses shown in Fig.10 are observed at the bottom of the tilting arm.[7]

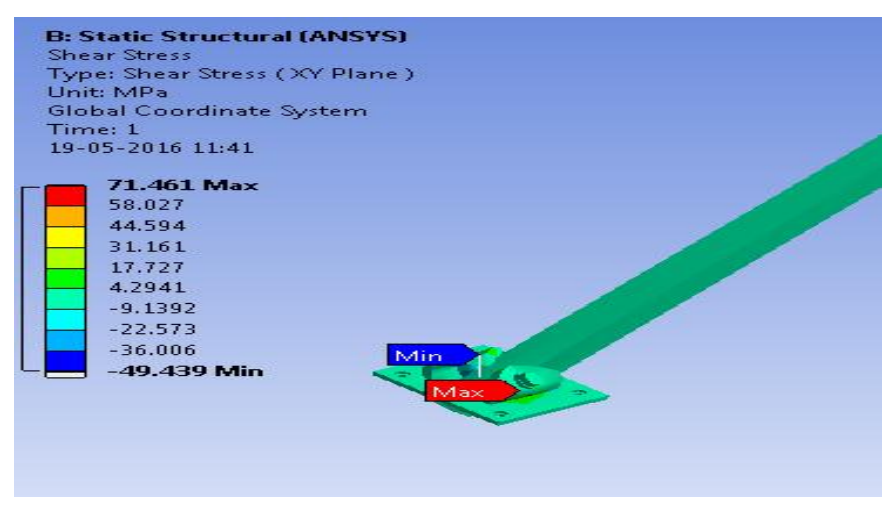

Fig.11. Shear stress occur 71.46 MPa

Similarly, in the design of the pin the maximum shear stress obtained by FEA is 71.461MPa as shown in Fig.11. The Fig.12 shows the meshed model of L-bracket. Hexahedral element is used for meshing of L bracket.[8]

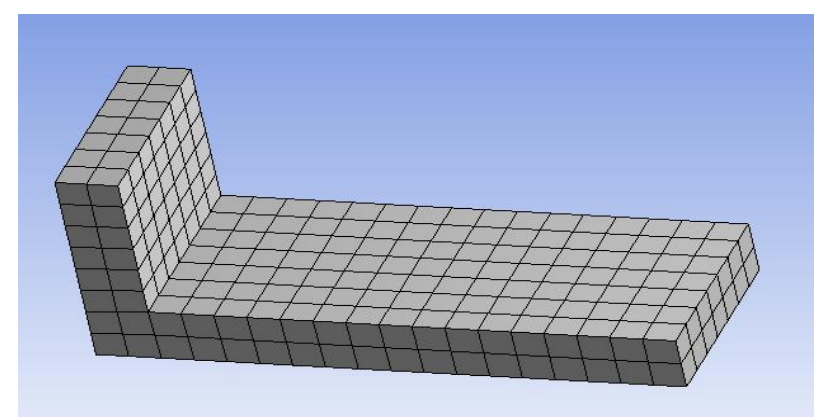

Fig.12. Meshed model of L-Bracket

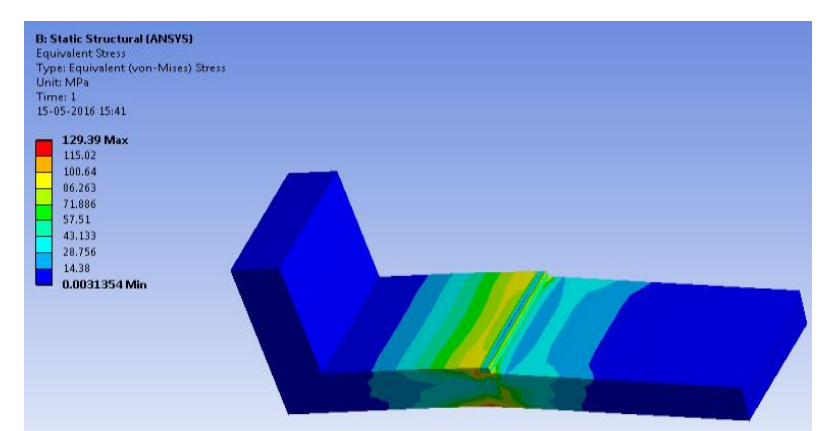

Fig.13. Von-mises stress of 129.39 MPa on L-Bracket

The finite element simulation shows maximum von-mises stresses on the L-bracket. The maximum von-mises stresses shown in Fig.13.

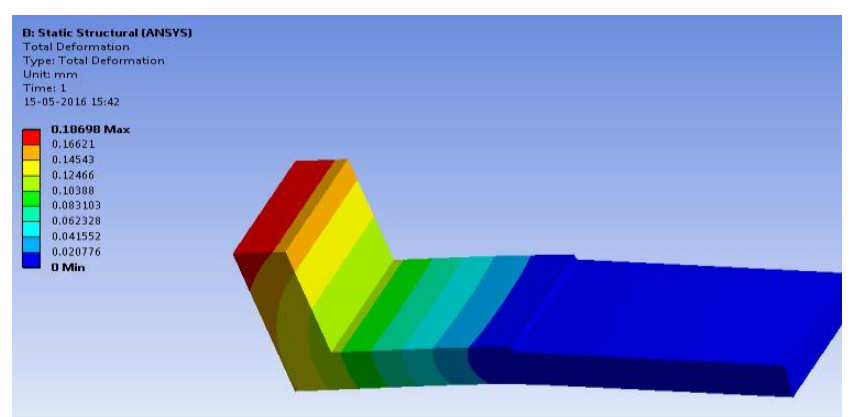

Fig.14. Total deformation of $0.18698 \mathrm{~mm}$ 
The FEA shows total deformation occurs over the L-Bracket shown in Fig 14. The comparison of different design stresses obtained by analytical and simulation methods are shown in the Table 3.

Table 3: Comparison of Analytical and FEA Results

\begin{tabular}{|c|c|c|c|c|}
\hline Component & Parameters & $\begin{array}{c}\text { Design Output } \\
(\mathrm{MPa})\end{array}$ & $\begin{array}{c}\text { CAE Output } \\
(\mathrm{MPa})\end{array}$ & $\begin{array}{c}\% \\
\text { Variation }\end{array}$ \\
\hline $\begin{array}{c}\text { Strut and } \\
\text { Pin }\end{array}$ & Working Stress & 125 & 111.67 & 10 \\
\hline Pin & Shear Stress & 79.6 & 71.46 & 10.22 \\
\hline L Bracket & $\begin{array}{c}\text { Maximum } \\
\text { Stress }\end{array}$ & 147 & 129 & 12.24 \\
\hline & Deflection & $0.18(\mathrm{~mm})$ & $0.18698(\mathrm{~mm})$ & 3 \\
\hline
\end{tabular}

\section{FEA RESULTS AND DISCUSSION}

Johnson's method of material selection yields output as SS 309 to be the best material for the design of the components of the system. The finite element analysis of tilting arm gives $10 \%$ to $15 \%$ variation with the bearing stress obtained by analytical method. In the design of the pin, it gives around $10 \%$ variation with analytical results. Similarly, in design of L-bracket stress variation is up to $12 \%$ and deformation is varying up to $3 \%$.

\section{CONCLUSION}

It is concluded that, as per the processing unit requirement the newly designed semicircular platform can be used to cover maximum area of the pressure vessel for performing the operations. Simultaneously, the Lbracket and arm are useful and critical components in the assembly. They were designed as per the requirement. Manufacturability is also feasible and simple assembly makes its working easier. The results obtained from the analytical methods shows good agreement with CAE results and also it shows that the design is safe under certain accepted parameter.

\section{REFERENCES}

[1] Jaydeep M. Bhatt, et al, Nov.12- Oct. 13, Design and analysis of an aerial scissor lift, Journal of Information, Knowledge and Research in Mechanical Engineering, ISSN 0975 - 668X, Volume-02, ISSUE -02,452.

[2] T. Islam, et al, Dynamic analysis of scissor lift mechanism through bond graph modeling, in Proceedings of the IEEE/ASME AI, the IEEE/ASME International Conference on Advanced Intelligent Mechatronics, 1-10, July 7 - 10, Besancon, France 2014.

[3] V.B.Bhandari, Design of Machine Element, 3/e (McGraw-Hill).

[4] F. Rahimi Dehgolan, et al, Obtaining constant of Johnson material model using expt., numerical simulation and optimization method, Jan 1999.

[5] Hartley T. Grandin, et al, Mechanics of material, Department of Mechanical Engineering Worcester Polytechnic Institute, University of Arkansas, ASEE New England Section Annual Conference, 2006.

[6] Helmi Rashid, et al, Design Review of Scissors Lifts Structure for Commercial Aircraft Ground Support Equipment using Finite Element Analysis, 2012.

[7] N. Martinsen, Tilting Bracket for Containers, Jan. 23, 1951.

[8] Veronika Bleaker, et al, lifting device for scissor lifts, U.S.Patent 0037765 A1, Feb. 14, 2013. 